Review article

\title{
The bladder is an unreliable witness: The case for urodynamic investigations in female stress urinary incontinence
}

\author{
Maurizio Seratia ${ }^{\mathrm{a}, *}$, Tufan Tarcan ${ }^{\mathrm{b}}$, Enrico Finazzi-Agrò ${ }^{\mathrm{c}}$, Marco Soligo $^{\mathrm{d}}$, Andrea Braga ${ }^{\mathrm{e}}$, \\ Stavros Athanasiou ${ }^{\mathrm{f}}$, Matteo Balzarro ${ }^{\mathrm{g}}$ \\ a Department of Obstetrics and Gynecology, University of Insubria, Varese, Italy \\ ${ }^{\mathrm{b}}$ Department of Urology, Marmara University School of Medicine and Koc University School of Medicine, Istanbul, Turkey \\ ${ }^{c}$ Department of Surgical Sciences, University of Rome Tor Vergata, Urology Unit, Tor Vergata University Hospital, Italy \\ 'Department of Women, Mothers and Neonates, Buzzi Children's Hospital, ASST Fatebenefratelli Sacco, University of Milan, Milan, Italy \\ e Department of Obstetrics and Gynecology, EOC - Beata Vergine Hospital, Mendrisio, Switzerland \\ ${ }^{\mathrm{f}}$ Department of Obstetrics and Gynecology, National and Kapodistrian University of Athens and Alexandra Hospital, Athens, Greece \\ ${ }^{g}$ Department of Urology, Azienda Ospedaliera Universitaria Integrata of Verona, Verona, Italy
}

\section{A R T I C L E I N F O}

Article history:

Received 21 September 2019

Received in revised form 25 October 2019

Accepted 29 October 2019

\section{Keywords:}

Stress urinary incontinence

Urodynamics

Mid-urethral sling

Surgery

\begin{abstract}
A B S T R A C T
For some years, the role of urodynamics (UDS) in female stress urinary incontinence (SUI) has been a topic of intense debate. The findings of the VaLUE and VUSIS-II randomised clinical trials (RCTs) published in 2012 appeared to suggest that UDS is not useful in women with uncomplicated SUI, with the result that several authoritative guidelines were amended and the routine use of UDS in this setting fell sharply. However, many experts have raised concerns about the design of these two RCTs and their subsequent interpretation - including the inappropriate generalisation of the findings beyond uncomplicated cases, which represent only a small minority of the overall patient population. In this paper, we consider a range of issues and confounding factors which raise doubts about how influential these RCTs should have been and reflect on the potential value of UDS both for objective diagnosis and patient counselling in female SUI.
\end{abstract}

(c) 2019 Elsevier B.V. All rights reserved.

\section{Contents}

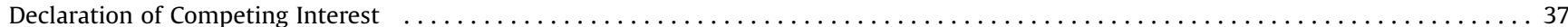

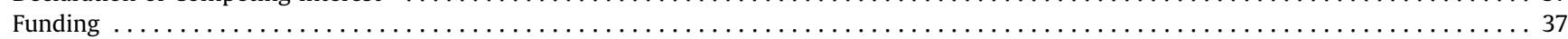

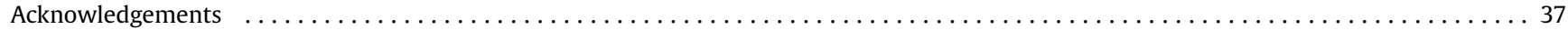

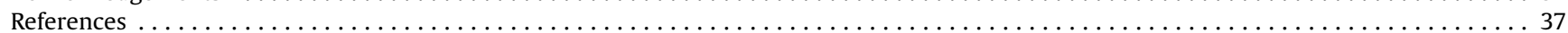

In the management of urinary incontinence, the concept of the bladder as "an unreliable witness" - i.e. that bladder symptoms do not always correlate with underlying pathology - is well accepted. In light of this, the value of objective diagnosis and assessment is recognized by many in the field, who perceive urodynamic investigations (UDS) as a useful tool in this setting [1-4]. However, precisely because the bladder is an unreliable witness, UDS investigations have in themselves posed some challenges. There is variability in UDS results among patients with similar clinical presentations [5,6] and the clinical diagnosis of SUI may not

\footnotetext{
* Corresponding author.

E-mail address: mauserati@hotmail.com (M. Serati).
}

correlate with UDS findings [7]. Moreover, Valsalva leak point pressure (VLPP) has never been standardized and its reliability as a measure has been questioned [8]. Lastly, measurement of the maximum urethral closure pressure (MUCP), for which reproducibility has also been debated $[9,10,11]$, correlates poorly with incontinence severity [12]. These issues, amongst others, have prompted ongoing scrutiny of the value and role of UDS.

In particular, an intense debate has developed in recent years over the role of UDS in women with stress urinary incontinence (SUI) who are potential candidates for surgical intervention. According to the latest recommendations of the International Continence Society (ICS) and International Consultation for Incontinence (ICI) in 2016 [13], UDS is viewed as unnecessary in cases of uncomplicated SUI, also called pure SUI (P-SUI). These 
recommendations, and others [14,15], were strongly influenced by two randomized controlled trials (RCTs) in women with P-SUI published in 2012 - the ValUE and VUSIS-II studies [16-18] - which concluded that UDS findings were not useful in this setting. However, both of these studies have sparked considerable controversy and criticism of their design and conclusions, as summarized in a recent European consensus article [19].

1 The first evident issue is the lack of a standardized definition of uncomplicated SUI. According to one definition, P-SUI is 'the involuntary loss of urine during physical exertion, effort, coughing or sneezing in the absence of a detrusor contraction without pain, hematuria, neurological conditions, recurrent UTIs, suspected voiding dysfunction, significant pelvic organ prolapse, previous urinary incontinence surgery, pelvic irradiation or surgery or suspected fistula'[13]. However, different authors use different terminologies, including 'uncomplicated SUI', 'P-SUI' and 'index patients with SUI', and a clear consensus on the definition is lacking.

2 A second - and major - issue relates to the fact that, in both of the studies, the vast majority of patients in both comparator arms received the same intervention: a synthetic mid-urethral sling (MUS):

3 The Value of Urodynamic Evaluation (ValUE) study, analyzed 585 women who underwent surgical procedures for P-SUI [15]. Patients were randomized to receive either empiric surgery or to undergo UDS beforehand. Of the 585 patients, a total of 545 (93 $\%$ in both groups) ultimately received a MUS.

4 The Value of Urodynamics prior to Stress Incontinence Surgery (VUSIS-II) study [16,17]. compared P-SUI patients treated empirically with MUS vs a tailored treatment approach based on UDS findings, that included detrusor overactivity treatments (anticholinergics, intravesical botulinum toxin injections or pretibial nerve stimulation), prolonged physiotherapy, bladder training in case of dysfunctional voiding, pessary placement, expectant management, and - significantly - also MUS In fact, $98 \%$ of patients in the tailored group received MUS, vs $97 \%$ in the empiric surgery group.

After analyzing the outcomes, the authors of both studies concluded that empiric use of MUS in women with P-SUI was not inferior to management based on UDS, and therefore UDS should no longer be routinely requested prior to surgery in these patients. A major confounding factor with these studies is that patients in both groups ended up with almost the same kind and number of procedures, which calls the tailoring into question and also casts doubt on why the eventual results of surgery in the two groups differed.

3 A third issue relates to the fact that - while meaningful results were available only for patients who received a MUS conclusions about the lack of need for UDS seem to have been assumed for other management approaches as well. The VUSISII study only looked at MUS. In the ValUE Study, 24 patients (4.1 $\%)$ received a traditional sling and $4(0.7 \%)$ received bulking agents [15]. These numbers were too low to reach statistical significance, with the inference that, at least with these two procedures, there are not enough data to justify the abandonment of urodynamic evaluation in women with PSUI.

The design of these two RCTs which have been so influential raise some fundamental conceptual questions. For example, would undertaking POP-Q staging of an anterior vaginal wall defect (AVWD) in one group of patients make sense if their surgical outcomes are then compared to a group who received the same intervention? Clearly, the answer is no. However, no-one would subject a patient to AWVD repair without clinical staging even though the staging might not change the management approach. With regard to the ValUE and VUSIS-II studies, it would also have been useful to understand the role of UDS across a range of surgical approaches, with adequate statistical power for each cohort.

Despite their important limitations, the publication of the ValUE and VUSIS-II studies prompted a drastic reduction in use of UDS prior to surgery for SUI in recent years. A 2018 Dutch survey on the strategy of "de-implementation" of UDS in women with P-SUI reported that $93 \%$ of urologists and gynecologists no longer perform UDS in this sub-population, and that $61 \%$ have changed their clinical practice in favour of abandoning UDS before MUS. However, the data also reveal that $45 \%$ of responders also don't carry out UDS in more complex, 'non-P-SUI' cases (i.e. presence of large PVR, a poor flow, or doubts regarding the reason for incontinence based on physical examination) [20]. Several of the authors of the survey - some of whom were themselves authors of the VUSIS-II study - considered it necessary to reiterate that the ValUE and VUSIS-II studies looked only at uncomplicated cases of SUI and that their findings "cannot be extrapolated to recommend no routine preoperative UDS before recurrent SUI or cases with concomitant prolapse" [21].

A recent US publication, which reviewed data on 387 women who underwent surgery for SUI either in 2008-9 (pre-VaLUE study) or in 2014-16 (post-VaLUE study), was similarly worrying. It reported that the rate of preoperative urodynamic testing in female candidates for MUS decreased from $70 \%$ to $41 \%$ after the publication of the ValUE trial. The authors voiced their support for this trend, stating their view that UDS does not change procedural decision-making [22]. However, analysis of the data in this study reveals a major discrepancy between the percentage of patients (59\%) that did not receive UDS following the ValUE trial and the incidence of P-SUI reported in the literature $(5.2-36 \%)[3,23]$. It is conceivable that this particular study population had almost double the highest incidence rate of P-SUI (36\%) [23] reported in the literature. A much more likely hypothesis is that, in $34 \%$ of nonP-SUI women, UDS was not seen as a necessary preoperative tool even in these more complex cases, mirroring the findings of the Dutch survey. It is important to recognize not only that the great majority of cases of SUI are not uncomplicated, but that UDS has been shown to have intrinsically greater benefit in complex cases than in P-SUI $[23,24]$ and that a wide range of prospective and retrospective studies have demonstrated the value of UDS in diverse SUI patient cohorts [19].

In routine clinical practice, the extent to which UDS is carried out prior to surgical treatment for SUI depends on a range of factors including the cost of the procedure, availability of suitably trained staff and technical expertise, the approach to patient counselling and the strength of the belief that performing UDS, despite its limitations, adds an element of objective physiological evidence that makes the assessment of the patient more holistic. In recent years, attention to healthcare spending has become a priority. There is no doubt that UDS investigations have a cost but comparing this cost in nations with national healthcare systems vs those with healthcare linked to insurance plans may produce different results $[3,23,25,26]$. In addition, the cost of UDS may be amortized, or even negated, if its use avoids unnecessary and unjustifiable surgical procedures or other inappropriate management strategies. A secondary analysis of the ValUE trial indicates that information from UDS rarely influenced surgeons to cancel, change or modify their planned surgery [25]. These data conflict with what is reported by other authors, for example Suskind et al. [27] who found that UDS prompted a change in therapeutic strategy in $42.5 \%$ of cases, $35 \%$ of which related to surgery. For every woman subjected to an unnecessary and unjustifiable surgical procedure, there is more than the wasted expense of the 
surgery itself to consider but also the trauma to the patient and the risk of complications, with their additional costs and burdens.

Patient counseling is a complex topic that has been described for the first time in urogynecology in a recent paper [28]. Counseling should involve explaining the underlying clinical problem and describing the likely outcome of the intended surgical procedure to help manage patient expectations. Our experience has shown that pathophysiological explanations relating to the detrusor pump and container functionality in particular are a valuable part of counselling. As an example, the potential benefits of MUS implantation in women with detrusor under-contractility is still a research field and the only study available on this topic reported that, in a population of 50 women with under-contractility, the cure rate with MUS was not significantly different from that in the normo-contractility group, but voiding dysfunctions were statistically significant higher [29]. As a result, the authors concluded that UDS investigations are useful for counseling purposes in this population. Other authors consider preoperative UDS justified in light of the fact that pre-existing detrusor overactivity (DO) may affect the outcome of surgery [18]. Good preoperative counseling improves relationships with patients, builds trust and improves satisfaction with treatment outcomes, particularly in cases where adverse events are experienced. Currently UDS is the only tool capable of providing useful information to inform counselling.

Of course, the world changes and what was true yesterday may not be so tomorrow. In recent years we have seen the demise of the vaginal mesh for pelvic organ prolapse (POP) that led the US Food and Drug Administration (FDA) to order the immediate cessation of sales and distribution of the mesh due to the escalating legal claims. The lack of robust data on the clinical performance of vaginal meshes and the rapid evolution of these products were cited as part of this ruling. After the FDA communication about meshes for POP, $63.3 \%$ of legal claims in the field were related to use of slings for SUI (single incision, retropubic and trans-obturator tapes) [30]. In this case, however, the rise in lawsuits does not reflect what is seen as an acceptably low rate of complications for SUI slings reported in the literature [30] and the availability of robust data on their effectiveness. Nevertheless, the widespread use of this intervention has recently been questioned in a number of countries.

In this scenario, UDS has multiple roles. It represents the only investigation that objectively evaluates the bladder/detrusor status of a female candidate for SUI surgery, improving surgeons' understanding of their condition, facilitating counseling, and enabling patients to play a role in decision-making. Moreover, UDS may help to justify the use of a MUS, or the avoidance of it, thus helping to ensure the most appropriate and targeted use of this intervention. Last but not least, should the MUS become reputationally damaged in the way the vaginal mesh was, UDS would be the only investigation able to evaluate the usefulness of other invasive procedures for P-SUI. As stated by Finazzi-Agro et al. [19], 'Empiric decision-making is considered bad practice in most other areas of medicine, with good reason'.

\section{Declaration of Competing Interest}

The authors declare that they have no known competing financial interests or personal relationships that could have appeared to influence the work reported in this paper.

\section{Funding}

None.

\section{Acknowledgements}

We thank Karen Lipworth for assistance with the preparation of this manuscript.

\section{References}

[1] Blaivas JG, Appell RA, Fantl JA, et al. Definition and classification of urinary incontinence: reccomendations of the urodynamic society. Neurourol Urodyn 1997; 16:149-51.

[2] Abrams P, Andersson KE, Birder L, et al. Fourth international consultation of the international scientificn committee: evaluation and treatment of urinary incontinence, pelvic organ prolapse, and fecal incontinence. Neurourol Urodyn 2010;29:213-40.

[3] Rubilotta E, Balzarro M, D’Amico A, Cerruto MA, Bassi S, Bovo C, et al. Pure stress urinary incontinence: analysis of prevalence, estimation of costs, and financial impact. BMC Urol 2019;19(June 1):44.

[4] Hashim H, Abrams P. Is the bladder a reliable witness for predicting detrusor overactivity? J Urol 2006;175:191-4.

[5] Brostrom S, et al. Short-term reproducibility of cystometry and pressure-flow micturition studies in healthy women. Neurourol Urodyn 2002;21:457.

[6] Broekhuis SR, et al. Reproducibility of same session repeated cystometry and pressure-flow studies in women with symptoms of urinary incontinence. Neurourol Urodyn 2010;29:428.

[7] Van Leijsen SA, et al. The correlation between clinical and urodynamic diagnosis in classifying the type of urinary incontinence in women. A systematic review of the literature. Neurourol Urodyn 2011;30:495.

[8] Albo ME, et al. Burch colposuspension versus fascial sling to reduce urinary stress incontinence. N Engl J Med 2007;356:2143.

[9] Dorflinger A, et al. Urethral pressure profile: is it affected by position? Neurourol Urodyn 2002;21:553.

[10] Wang AC, et al. A comparison of urethral pressure profilometry using microtip and dauble-lumen perfusion catheters in women with genuine stress incontinence. BJOG 2002;109:322.

[11] Zehnder P, et al. Air charged and microtip catheters cannot be used interchangeably for urethral pressure measurement: a prospective, singleblind, randomized trial. J Urol 2008;180:1013.

[12] Schick E, et al. Predictive value of maximum urethral closure pressure, urethral hypermobility and urethral incompetence in the diagnosis of clinically significant female genuine stress incontinence. J Urol 2004;171(1871).

[13] Abrams P, Cardozo L, Wagg A, Wein A, editors. Incontinence. 6th edition Bristol UK: ICI-ICS. International Continence Society; 2017 ISBN: 978-0956960733.

[14] https://uroweb.org/guideline/urinary-incontinence/\#3, 3.6.3.

[15] Winters JC, Dmochiowski RR, Goldman HB, et al. Adult urodynamics: AUA/ SUFU guideline. J Urol 2012;188(Suppl):2464-72.

[16] Nager CW, et al. A randomized trial of urodynamic testing before stressincontinence surgery. N Engl J Med 2012;366(1987).

[17] Van Leijsen SAL, Kluivers KB, Mol BWJ, et al. Protocol for the value of urodynamics prior to stress incontinence surgery (VUSIS) study: a multicenter randomized controlled trial to assess the cost effectiveness of urodynamics in women with symptoms of stress urinary incontinence in whom surgical treatment is considered. BMC Womens Health 2009;21(July 9):22.

[18] Van Leijsen SA, Kluivers KB, Mol BW, et al. Value of urodynamics before stress urinary incontinence surgery: a randomized controlled trial. Obstet Gynecol 2013;121(May 5):999-1008.

[19] Finazzi-Agro E, Gammie A, Kessler TM, et al. Urodynamics useless in female stress urinary incontinence? Time for some sense - a European expert consensus. Eur Urol Focus 2018;27, doi:http://dx.doi.org/10.1016/j. euf.2018.07.031 Jul.

[20] Mengerink BB, WLDM Nelen, van Leijsen SAL, et al. De-implementation of urodynamics in the Netherlands after the VALUE/VUSIS-2 results: a nationwide survey. Int Urogynecol J 2018;29(September 9):1261-77.

[21] Mengerink BB, WLDM Nelen, van Leijsen SAL, et al. De-implementation of urodynamics in the Netherlands after the VALUE/VUSIS-2 results: a nationwide survey. Int Urogynecol J 2018;29(September 9):1279-80.

[22] Lioyd JC, Dielubanza E, Goldman HB. Trends in urodynamic testing prior to midurethral sling placement-What was the value of the VALUE trial? Neurourol Urodyn 2018;37(March 3):1046-52.

[23] Serati M, Topazio L, Bogani G, et al. Urodynamics useless before surgery for female stress urinary incontinence: are you sure? Results from a multicenter single nation database. Neurourol Urodyn 2016;35:809-12.

[24] Del Popolo G, Li Marzi V, Serati M. Do preoperative urodynamics still have a role in female stress urinary incontinence? Neurourol Urodyn 2013;32: $1144-5$.

[25] Norton P, Nager CW, Brubaker L, et al. The cost of preoperative urodynamics: a secondary analysis of the ValUE trial. Neurourol Urodyn 2016;35(January 1):81-4.

[26] Digesu GA, Hendricken C, Fernando R, et al. Do women with pure stress urinary incontinence need urodynamics? Urology 2009;74:278-81.

[27] Suskind AM, Cox L, Clemens JQ, et al. The value of urodynamics in an academic specialty referral practice. Urology 2017;105:48-53.

[28] Balzarro M, Rubilotta E, Goss C, et al. Counseling in urogynecology: a difficult task, or simply good surgeon-patient communication? Int Urogyncol J 2018;29 (July 7):943-8

[29] Natale F, Illiano E, Zucchi A, et al. Transobturator mid-urethral sling in females with stress urinary incontinence and detrusor underactivity: effect on voiding phase. Int Urogynecol J 2019;4 Feb.

[30] Souders CP, Eilber KS, McClelland L, et al. The truth behind transvaginal mesh litigation: devices, timelines, and provider characteristics. Female Pelvic Reconstr Surg. 2018;24(Jan/Feb 1):21-5. 